\title{
Antigenic analysis of bovine Sarcocystis spp. in Sri Lanka
}

\author{
D.C. Hettiarachchi ${ }^{1 *}$ and R.P.V.J. Rajapakse ${ }^{2}$ \\ 1 47/5, Maitland Place, National Science Foundation, Colombo 7. \\ ${ }^{2}$ Department of Veterinary Pathobiology, Faculty of Veterinary Medicine \& Animal Science, University of Peradeniya, Peradeniya.
}

Revised: 04 April 2008 ; Accepted: 20 June 2008

\begin{abstract}
Sarcocystis is an intracellular parasite, known to cause acute and chronic diseases in a variety of animal hosts, including cattle. Sarcocystis has also been reported as a zoonotic form and causes cysts in meat resulting in economic losses. This study was designed to characterize Sarcocystis antigens by molecular weight and to investigate the possibility of crossreaction with related Apicomplexan Toxoplasma gondii.
\end{abstract}

Sarcocystis antigen was prepared by chemical lysis (10\% Triton) of bradyzoites/cystozoites contained in tissue cysts. Healthy rabbits were inoculated with Sarcocystis (antigen and whole parasite) and Toxoplasma and antibodies were harvested after a month. A higher antibody titre was elicited by the inoculation of Sarcocystis cystozoites as opposed to the antigen. The latex agglutination test confirmed the presence of anti Toxoplasma antibodies in test serum and negated cross-reactivity between Sarcocystis and T. gondii at 1:100 serum dilution. Immunoblot results also did not support cross-reactivity. Sodium dodecyl sulphate polyacrylamide gel electrophoresis (SDS-PAGE) and subsequent immunoblot analysis at 1:100 serum dilution revealed twelve antigenic bands, three of which were prominent. Out of these three, two were complex bands of $\sim 66 \mathrm{kMW}$ and above. The other was a single band of $\sim 45 \mathrm{kMW}$. Monoclonal antibodies can be developed against these potent antigens for diagnostic purposes in the future.

Keywords: Antigens, cross-reactivity, protozoan parasite, Sarcocystis, Sri Lanka, Toxoplasma

\section{INTRODUCTION}

Sarcocystis is a protozoan parasite causing acute and chronic diseases in its intermediate hosts, commonly cattle and sheep. It is responsible for abortion, acute illness, growth retardation and ultimately death in livestock, generating significant economic losses. The presence of sarcocysts in meat can lead to a parasitic hazard in humans ${ }^{1}$. The beef industry in Sri Lanka is affected by condemnation of the carcasses of infected cattle at the time of inspection (personal communication with the meat inspectors at the Colombo Municipal Abattoir). Infected female cattle undergo abortion and weight reduction ${ }^{2}$. The low milk production negatively affects the milk industry.

Previous studies have portrayed Sarcocystis as a zoonotic parasite. The dissemination of Sarcocystis to animals largely depends on human factors and the human is also an essential part of the life cycle ${ }^{3}$ for the two species $S$. hominis and S. suihominis. In a developing country such as Sri Lanka, poor hygienic conditions and traditional farm practices may facilitate contact between human and parasite, thereby increasing the risk of infection of humans. Three species of Sarcocystis, namely S.cruzi (S.bovicanis), S.hirsute (S.bovifelis) and S. hominis (S.bovihominis) were found to occur in cattle of Sri Lanka, by a study based on cyst morphology ${ }^{4}$. The definitive diagnosis of Sarcocystis has traditionally been accomplished through inspection of cattle carcasses at the abattoir. Infected animals are not detected due to repressed pathological symptoms. Currently, there is no effective prophylaxis or therapy for the disease caused by S.cruzi, which is generally referred to as sarcocystosis 5 . Livestock should be diagnosed routinely and the infected animals quarantined to prevent the spread of this parasite.

The primary objective of this study was to characterize antigens of Sarcocystis by molecular weight in order to facilitate development of a precise diagnostic tool. The SDS-Polyacrylamide Electrophoresis (SDSPAGE) technique was employed for this study, as this approach allows separate visualization of each antigenic 
polypeptide band in a complex protein mixture, unlike the enzyme linked immunosorbent assay (ELISA). Analysis and characterization of parasite antigen can be achieved by the Western blot. This technique is justified by the fact that many proteins retain their antigenicity when transferred from Polyacrylamide gels onto Nitrocellulose filters ${ }^{5}$. The Western blot has been the preferred method for testing seroprevalence of Sarcocystis, Toxoplasma and Neospora antigens ${ }^{6,7}$.

The possibility of cross-reaction with similar protozoa must be explored for correct interpretation of the results of a serological test. Hence, this study was expanded to investigate the possibility of cross-reaction with related Apicomplexan, Toxoplasma gondii, in light of the inconsistent results observed in the past (mentioned in detail in the Discussion) ${ }^{5-9}$. Both these parasites produce cysts in host tissue and it may be difficult to differentiate each symptom of sarcocystosis and toxoplasmosis ${ }^{10}$. Although infection with Sarcocystis is very common in cattle throughout the world, T.gondii has rarely been identified from bovine tissues. The frequent demonstration of antibodies in serum suggests however, that unapparent Toxoplasma infection may be common ${ }^{5}$.

\section{METHODS AND MATERIALS}

Macroscopically visible sarcocysts were obtained from the thigh muscle of heavily infected cattle carcasses at the Colombo Municipal Abattoir by identifying the gross morphology. These cysts were narrow, elongated and cream/white in colour (Figure 1). They were teased out of the muscle with fine forceps, collected into phosphate buffered saline (PBS) and transported in an icebox. In the laboratory the specimens were stored at $-20^{\circ} \mathrm{C}$.

Toxoplasma was obtained in the trachyzoite stage from a previously established and cryopreserved vero cell culture of the Faculty of Veterinary Medicine and Animal Science, University of Peradeniya, Peradeniya. The vial of trachyzoites was kept in a $-20{ }^{\circ} \mathrm{C}$ freezer and thawed immediately prior to use.

Ten sarcocysts were collected into an eppendorf tube and washed with saline thrice to remove attached bovine tissue. Using fine forceps the cysts were macerated in $100 \mu \mathrm{L}$ of saline at room temperature until a creamcoloured suspension formed. A drop of the suspension was examined under the light microscope ( $\mathrm{x} 40$ ) to confirm presence of banana-shaped cystozoites. These cystozoites were centrifuged, resuspended in PBS, recentrifuged and the supernatant discarded. The pellet of cystozoites was mixed with about $10 \mathrm{~mL}$ of $50 \%$ isotonic
Percoll solution in a conical tube and centrifuged at $400 \mathrm{~g}$ for $10 \mathrm{~min}^{11}$. Extraction buffer consisting of $180 \mu \mathrm{L}$ PBS and $20 \mu \mathrm{L} 10 \%$ Triton (TritonX-100, BDH laboratory, BDH Chemical Australia Pvt. Ltd., Victoria 3284, Australia) in PBS was then added to the eppendorf. The sample was mixed well by a whirly mixer for $5 \mathrm{~min}$, while alternatively placing it in ice to avoid heating. The sample was then centrifuged for $10 \mathrm{~min}$ at $14000 \mathrm{rpm}$ in $4{ }^{\circ} \mathrm{C}$. The resulting supernatant (antigen) was collected as aliquots into eppendorfs and stored at $-20^{\circ} \mathrm{C}$.

The Toxoplasma culture was washed thrice with saline in an eppendorf and subjected to the lysis buffer (0.5 M Tris HCl, 10\% SDS, DiThioThreitol, distilled water) for $10 \mathrm{~min}$. The resulting antigen suspension was stored in $-20^{\circ} \mathrm{C}$.

Cattle tissue was macerated in $100 \mu \mathrm{L}$ of saline at room temperature using fine forceps. This sample was then centrifuged for $10 \mathrm{~min}$ at $10000 \mathrm{rpm}$ in $4{ }^{\circ} \mathrm{C}$. The resulting supernatant (antigen) was collected as aliquots into eppendorfs and stored in $-20{ }^{\circ} \mathrm{C}$.

The dot blot-ELISA ${ }^{12}$ was used to check the antigen sample for host protein contamination. Two dots were impregnated with $1 \mu \mathrm{L}$ of Sarcocystis antigen and $1 \mu \mathrm{L}$ host tissue preparation separately. They were incubated with peroxide conjugated anti-bovine IgG (Sigma Chemicals, St.Luise, USA) at a 1:200 dilution. No colour development in the antigen-impregnated dot suggested that host protein contamination in the prepared antigen was negligible, if any, and that it can be used for further analysis.

For estimation of protein quantity in the antigen preparation the Bicinchoninic acid protein assay kit No. BCA 1 (Sigma Chemicals, St. Luise, USA) and Sigma procedure no. TPRO 562 were used. A standard curve was prepared by plotting the net absorbance at $562 \mathrm{~nm}$ versus the concentration of known protein standards. This curve was used to determine the amount of protein in the Sarcocystis antigen sample. Using this value the true concentration of proteins in the antigen preparation was calculated as follows:

mg antigen per assay from standard curve $\mathrm{x}$ dilution factor

Volume $(\mathrm{mL})$ of antigen sample used for assay

Four laboratory bred (Medical Research Institute, Borella) New Zealand white rabbits of $\sim 3$ months of 
age were labelled as R1, R2, R3 and R4. They were fed on Broiler Finisher and guinea grass throughout the experiment. After a week of orientation, the rabbits were bled and pre-immunization serum samples collected. As these samples tested negative for Sarcocystis and Toxoplasma infection by a dot blot assay (as previously described), the four rabbits were inoculated intramuscularly (IM) on the $21^{\text {st }}$ of February and subcutaneously (SC) on the $2^{\text {nd }}$ and $9^{\text {th }}$ March (Table 1). Freund's incomplete adjuvant (Sigma Chemicals, St. Luise, USA) was mixed with the respective antigens ${ }^{13}$ within $2.5 \mathrm{~mL}$ syringes, just before inoculation.

Blood ( $\sim 4 \mathrm{~mL})$ was drawn from the central artery of the ear ${ }^{14}$ of each rabbit on three days $\left(15^{\text {th }}, 23^{\text {rd }}\right.$ and $30^{\text {th }}$ of March) in order to select a serum sample with the highest concentration of antibodies. The serum for each animal, for each of the three collection dates, was stored in an eppendorf tube at $-20^{\circ} \mathrm{C}$.

The dot blot assay was used to detect presence of anti Sarcocystis and anti Toxoplasma antibodies in the collected serum. The Sarcocystis antigen imbibed dots were incubated with anti Sarcocystis serum of each animal (R2, R4), for each collection date. The three Toxoplasma antigen imbibed dots were incubated with anti Toxoplasma serum of R1 rabbit for each collection date. Out of the six PBS imbibed dots, three were incubated with anti Sarcocystis serum (of R2, R4) and the other three with anti Toxoplasma serum (of R1) for each collection date. Serum was thus tested at 1:100 dilution. Incubation with Peroxidase conjugated anti rabbit IgG (1:4000, Sigma Chemicals, St. Luise, USA) was followed by the chromogen solution (Amino Ethyl Carbazole $20 \mathrm{mg}$; Dimethyl formamide $2.5 \mathrm{~mL}$; Acetate buffer $47.5 \mathrm{~mL} ; 30 \% \mathrm{H}_{2} \mathrm{O}_{2} 25 \mu \mathrm{L}$ ). The rabbit serum which gave a colour reaction was used as positive serum for further analysis.

As a relatively low colour reaction was observed for anti Toxoplasma serum in the dot blot, the latex agglutination test ${ }^{15}$ was performed to confirm the presence of anti Toxoplasma antibodies. Previous studies have shown that latex agglutination test is high in sensitivity ${ }^{16}$ and is an effective method for routine serological screening for $T$. gondii antibodies .

Anti Toxoplasma serum sample was diluted with serum diluting buffer in a microtitre plate, starting at 1:25 up to1: 400. Anti Sarcocystis serum sample was diluted with serum diluting buffer (0.01 M phosphate buffered saline or PBS) in the same plate, starting at 1:25, upto 1: 100. Diluted (1:200) Toxoplasma positive human serum and Toxoplasma negative human serum were the positive and negative controls, respectively. The antigen mixture was freshly prepared with $2.5 \mathrm{~mL}$ antigen diluting buffer ( $0.4 \mathrm{~g}$ bovine serum albumin in $100 \mathrm{~mL}$ borate buffer), 35 $\mu \mathrm{L}$ 2-Mercaptoethanol, $50 \mu \mathrm{L}$ Evans Blue dye solution (2 $\mathrm{mg} / \mathrm{mL}$ water) and $0.15 \mathrm{~mL}$ of antigen (formalin fixed parasite). Agglutination was done in the microtitre plate. Twenty five $\mu \mathrm{L}$ of antigen mixture were pipetted out to each well immediately after mixing followed by $25 \mu \mathrm{L}$ of appropriate serum dilutions and mixed gently by repeated pipetting action. Then, plates were covered with sealing tape and incubated at $37^{\circ} \mathrm{C}$ overnight.

The Mini gel apparatus (Bio-Rad, Hercules, CA, USA) with a $12 \%$ Polyacrylamide gel was used to carry out electrophoresis for $50 \mathrm{~min}$ (stacking gel:100 V, $15 \mathrm{~min}$ and separating gel:200 V, $35 \mathrm{~min}$ ). The immunoblot ${ }^{17}$ was used to analyze the antigenic properties of the electrophoretically separated proteins.

Table 1: Inoculation of rabbits with Sarcocystis \& Toxoplasma antigens

\begin{tabular}{|c|c|c|c|c|}
\hline \multirow{2}{*}{$\begin{array}{l}\text { Date and type } \\
\text { of inoculation }\end{array}$} & \multicolumn{4}{|c|}{ Rabbits inoculated } \\
\hline & $\mathrm{R} 1$ & $\mathrm{R} 2$ & $\mathrm{R} 3$ & $\mathrm{R} 4$ \\
\hline $\begin{array}{l}21^{\text {st }} \text { February } \\
\text { (IM) }\end{array}$ & $\begin{array}{c}\text { Toxoplasma } \\
\text { antigen }+ \\
\text { incomplete } \\
\text { adjuvant(1:1) } \\
\sim 0.5 \mathrm{~mL}\end{array}$ & $\begin{array}{c}\text { Sarcocystis } \\
\text { bradyzoites }+ \\
\text { Incomplete } \\
\text { adjuvant(1:1) } \\
\sim 0.5 \mathrm{~mL}\end{array}$ & $\begin{array}{c}\text { PBS + } \\
\text { incomplete } \\
\text { adjuvant(1:1) } \\
\text { as control } \\
\sim 0.5 \mathrm{~mL}\end{array}$ & $\begin{array}{c}\text { Sarcocystis } \\
\text { antigen }+ \\
\text { Incomplete } \\
\text { adjuvant(1:1) } \\
\sim 0.5 \mathrm{~mL}\end{array}$ \\
\hline $\begin{array}{l}2^{\text {nd }} \text { March } \\
\text { (SC) }\end{array}$ & $\begin{array}{c}\text { Toxoplasma } \\
\text { antigen } \\
\sim 0.2 \mathrm{~mL}\end{array}$ & $\begin{array}{c}\text { Sarcocystis } \\
\text { bradyzoites } \\
\sim 0.2 \mathrm{~mL}\end{array}$ & $\begin{array}{c}\text { PBS } \\
\sim 0.2 \mathrm{~mL}\end{array}$ & $\begin{array}{l}\text { Sarcocystis } \\
\text { antigen } \\
\sim 0.2 \mathrm{~mL}\end{array}$ \\
\hline $\begin{array}{l}4^{\text {th }} \text { March } \\
\text { (SC) }\end{array}$ & $\begin{array}{c}\text { Toxoplasma } \\
\text { antigen } \\
\sim 0.2 \mathrm{~mL}\end{array}$ & $\begin{array}{l}\text { Sarcocystis } \\
\text { bradyzoites } \\
\sim 0.2 \mathrm{~mL}\end{array}$ & $\begin{array}{c}\text { PBS } \\
\sim 0.2 \mathrm{~mL}\end{array}$ & $\begin{array}{c}\text { Sarcocystis } \\
\text { antigen } \\
\sim 0.2 \mathrm{~mL}\end{array}$ \\
\hline
\end{tabular}

$\mathrm{IM}=$ intramuscular $; \mathrm{SC}=$ subcutaneous 
In the SDS-Page, the positive control (serum from R3) was run in two lanes, in order to compare the banding patterns between each sample more accurately.

\section{RESULTS}

The concentration of protein in the cystozoite antigen (Ag) preparation, as determined by the Bicinchoninic acid test, was $3.02 \mathrm{mg} / \mathrm{mL}$. Serum samples collected from rabbits on the $15^{\text {th }}$ of March showed negative results in the dot blot assay. However, serum collected on the $23^{\text {rd }}$ and the $30^{\text {th }}$ of March tested positive for antigens in the immunoblot, with a stronger result for the samples collected on the $30^{\text {th }}$ of March. Therefore, serum samples collected on the $30^{\text {th }}$ of March were selected for the antigen analysis.

The results of the dot blot indicated that the serum sample collected from rabbit R1 was positive for Toxoplasma and that those collected from R2 and R4 were positive for Sarcocystis. A comparatively strong colour development was observed in the serum sample from R2 suggesting a high antibody titre and hence, this sample was selected to represent Sarcocystis antigens.

The latex agglutination test yielded positive results for all the serial dilutions of anti Toxoplasma serum by expressing a clear solution in the appropriate wells (A1-

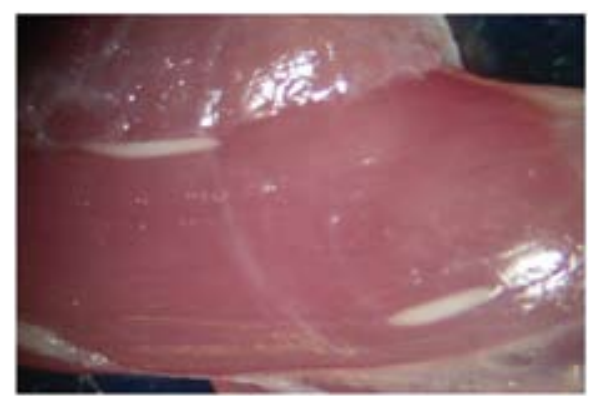

Figure 1: Sarcocysts in muscle tissue of cattle $(10 \times 40)$

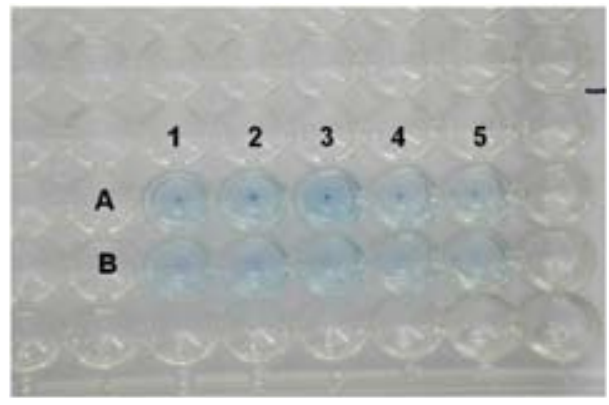

Figure 2: Latex agglutination test

$\mathrm{A}_{1}-\mathrm{A}_{4}=$ anti Sarcocystis positive serum, $\mathrm{A}_{5}=$ negative control,

$\mathrm{B}_{1}-\mathrm{B}_{4}=$ anti Toxoplasma positive serum, $\mathrm{B}_{5}=$ positive control
A5) of the microtitre plate. (Figure 2) The wells containing anti Sarcocystis serum and Toxoplasma antigen together showed a blue dot at the bottom, a negative result.

In the immunoblot and serum incubation, Ponceau $\mathrm{S}$ staining of the nitrocellulose blot revealed a significant protein-banding pattern for the Sarcocystis antigen preparation (Figure 3). Seven bands were distinct. Three bands were visualized between the 66-45 kMW markers and one band was approximately $45 \mathrm{kMW}$. Yet another band appeared to be slightly over $29 \mathrm{kMW}$. Two bands between 20 and $29 \mathrm{kMW}$ were also visualized.

The immunoblot incubated with anti Sarcocystis serum showed a clear and distinct banding pattern (Figure 4). Three prominent bands were identified, two complex, one single. One of the 2 complex bands was approximately $66 \mathrm{kMW}$ while the other had a higher molecular weight. The single band was approximately 45 kMW. The rabbit antiserum also reacted with nine other antigens. Seven of these bands were low in intensity and the other two faintly visible. No bands appeared for the fetal calf serum and Toxoplasma samples. The rabbit serum (positive control) yielded one conspicuously thick band. Three bands, one prominent and two of low intensity, appeared for the Toxoplasma sample lane of the blot incubated against anti Toxoplasma serum (Figure 5). No banding was seen for the Sarcocystis sample lane.

\section{DISCUSSION}

The antigens of Sarcocystis spp. infecting cattle, without discriminating between the different species, were investigated in this study. Cystozoites were chosen as the antigen source due to their high availability in abattoirs. A sufficient antibody titre was elicited against the cystozoites (in R2). Inoculation of the rabbit with the whole parasite (cystozoite) yielded better results in the dot blot than inoculation with the prepared antigen.

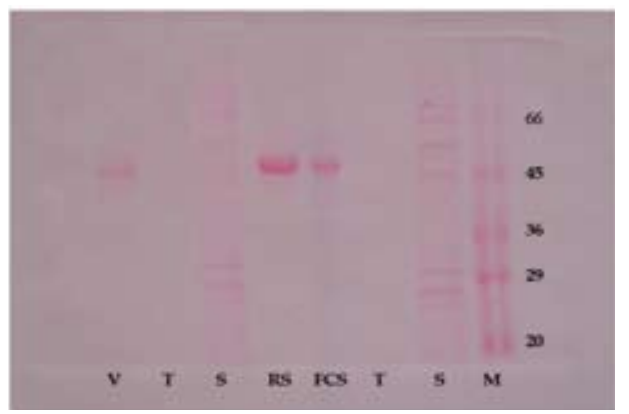

Figure 3: Western blot with Ponceau $S$ stain

$\mathrm{R}=$ rabbit serum (from $\mathrm{R} 3$ ), $\mathrm{T}=$ Toxoplasma $\mathrm{Ag}$ (from $\mathrm{R} 1$ ), $\mathrm{S}=$ Sarcocystis Ag (from R2), $\mathrm{F}=$ fetal calf serum, $\mathrm{V}=$ vero cells, $\mathrm{M}=$ molecular marker $/ \mathrm{kMW}$ 


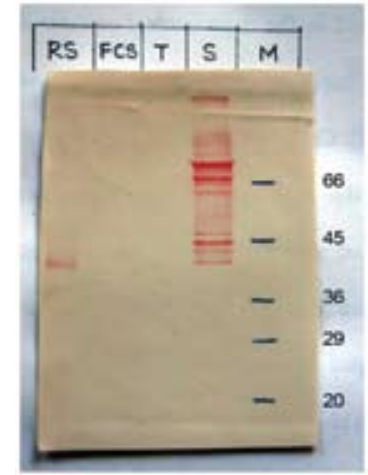

Figure 4: Immunoblot, incubated with anti Sarcocystis serum

$\mathrm{RS}=$ rabbit serum (from R3), FCS=fetal calf serum, $\mathrm{T}=$ Toxoplasma Ag (from R1), $\mathrm{S}=$ Sarcocystis Ag (from R2), $\mathrm{M}=$ molecular marker/kMW

Infection of Sarcocystis (as studied in S.cruzi) normally leads to serological patterns similar to other parasitic diseases. Initial production of specific IgM antibody is subsequently followed by production of IgG antibodies, and the latter remain at high levels for a longer period. A persistent and often slowly rising IgG response seems to appear approximately five weeks post infection (pi) in sheep and cattle ${ }^{18}$. In the present study, the IgG response in rabbits was first detected 31 days pi (dpi). This response elevated by $38 \mathrm{dpi}$ and the corresponding sera were thus used for the immunoblot.

The results of the immunoblot are consistent with previous serological studies that have used monoclonal anitibodies (Mabs) ${ }^{11}$. Two prominent cystozoite antigens of 45.5 and $64 \mathrm{kMW}$ were recognized in the above study whereas the present study identified two bands of $\sim 45$ and $\sim 66 \mathrm{kMW}$ respectively. Another strong band was also observed above the $66 \mathrm{kMW}$ marker in this study. It cannot be said at this point which, if any, of the molecules of Sarcocystis identified by rabbit hyper-immune sera may be surface molecules.

Sarcocystis bands did not appear below the $36 \mathrm{kMW}$ marker although protein bands were seen at that same level in the Ponceau S stained blot. A plausible reason for this absence may be the denaturation of epitopes during the SDS-PAGE procedure. Extreme sensitivity to endogenous proteases could have also caused destruction of epitopes on surface antigens ${ }^{11}$.

Cross-reactivity between Sarcocystis spp. and $T$. gondii has been investigated in the past, as the possibility cannot be overlooked during routine diagnosis. In 1971, the indirect florescence antibody test and Sabin-

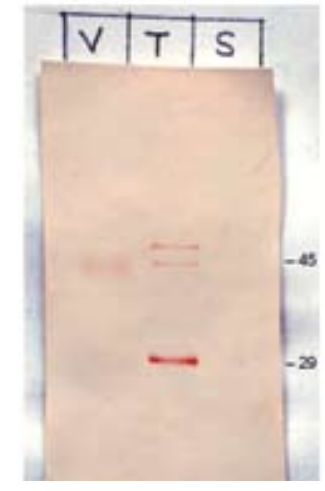

Figure 5: Immunoblot, incubated with anti Toxoplasma serum

$\mathrm{V}=$ vero cells, $\mathrm{T}=$ Toxoplasma Ag (from R1), $\mathrm{S}=$ Sarcocystis Ag (from $\mathrm{R} 2$ )

Feldman test delivered a negative verdict for crossreactivity as only specific reactions had occurred ${ }^{10}$.In 1977, antigens of Sarcocystis cystozoites from cattle did not cross-react with serum of humans naturally infected with $T$. gondii ${ }^{19}$. In 1984, sera from 2 calves inoculated 28-45 days previously with $5 \times 10^{4} \mathrm{~T}$. gondii oocysts showed no reaction with S.cruzi antigen by means of ELISA. However a study ${ }^{9}$ in 1987 described a very contrasting outcome in the cross reactivity tests. Savini ${ }^{5}$ was also able to demonstrate by the ELISA that cross-reactions occur between $T$. gondii and $S$. cruzi. In the present study, no cross reactivity was evident either in the immunoblot or the latex agglutination test. Toxoplasma antigen did not react with antibodies to Sarcocystis, or vice versa. Due to this inconsistency in results, it is necessary to investigate possible cross-reaction, when conducting diagnostic procedures for Sarcocystic and Toxoplasma infection. A sensitive test should be developed to ascertain cross reactivity.

\section{Acknowledgement}

The technical support extended by the staff of the Department of Veterinary Pathobiology, Faculty of Veterinary Medicine \& Animal Science, University of Peradeniya and the financial support offered by the Asian Development Bank are gratefully acknowledged.

\section{References}

1. Bottner A., Chalerston W.A.G., Pomroy W.E. \& Rommel M. (1987). The prevalence and identity of Sarcocystis in beef of cattle in New Zealand. Veterinary Parasitology 24(3-4): 157-168. 
2. Fayer R. \& Elsasser T.H. (1991). Bovine sarcocystosis: how parasites negatively affect growth. Parasitology Today 7(9): 250-255.

3. Savini G., Dunsmore J.D. \& Robertson I.D. (1993). Sarcocystis spp. in Western Australia sheep. Australian Veterinary Journal 70 (4): 152-154.

4. Gunawardena G.S., Navaratna M., Algama H.M.L.K., Dharmawardana I.V.P. \& Gammula Y. (1996). Prevalence of Sarcocystis in slaughtered cattle and goats in Sri Lanka. Proceedings of the $52^{\text {nd }}$ Annual Session, Sri Lanka Association for Advancement of Science p. 2.

5. Savini G. (1994). The epidemiology of Sarcocystis in Western Australia. Ph.D. Thesis, School of Veterinary Studies, Murdoch University, Murdoch 6150, W.A. Australia.

6. Gupta G.D., Lakritz J., Kim J.H., Kim D.Y., Kim J.K. \& Marsh A.E. (2002). Seroprevalence of Neospora, Toxoplasma gondii and Sarcocystis neurona antibodies in horses from Jeju Island, South Korea. Veterinary Parasitology 106 (3):193-201.

7. Rossano M.G., Kaneene J.B., Marteniuk J.V., Banks B.D., Schott H.C. \& Mansfield L.S. (2001). Preventive Veterinary Medicine 48 (2): 113-128.

8. Tadros W. \& Laarman J.J. (1982). Current concepts on the biology, evolution and taxonomy of tissue cyst-forming Eimeriid-coccidia. Advanced Parasitology 20: 293-468.

9. Uggla A., Hilali M. \& Lovgren K. (1987). Serological responses in Sarcocystis cruzi infected calves challenged with Toxoplasma gondii. Research in Veterinary Science 43 (1): 127-129.

10. Moon M.H. (1987). Serological cross-reactivity between Sarcocystis and Toxoplasma in pigs. The Korean Journal of Parasitology 25(2): 188-194.

11. Burgess D.E., Speer C.A. \& Reduker D.W. (1988). Identification of antigens of Sarcocystis cruzi sporozoites, merozoites and bradyzoites with monoclonal antibodies. Journal of Parasitology 74 (5): 828-832.

12. Marsh A.E., Hyun C., Barr B.C. \& Tindall R. (2002). Characterization of monoclonal antibodies developed against Sarcocystis neurona. Parasitology Research $\mathbf{8 8}$ (6): 501-506.

13. O'Donoghue P.J. \& Weyreter H. (1983). Detection of Sarcocystis antigens in the sera of experimentally infected pigs and mice by immunoenzymatic assay. Veterinary Parasitology 12 (1): 13-29.

14. Laber-Laird K., Swindle M.M. \& Flecknell P. (1996). Handbook of Rodent and Rabbit Medicine, first edition, Pergamon Veterinary Handbook Series, ButterworthHeinemann, Oxford, UK.

15. Dubey J.P., Desmonts G., Antunes F. \& McDonald C. (1985). Serological diagnosis of toxoplasmosis in experimentally infected pregnant goats and transplacentally infected kids. American Journal of Veterinary Research 46(5): 1137-1140.

16. Mazumder P., Chuang H.Y., Wentz M.W. \& Wiedbrauk D.L. (1988). Latex agglutination test for detection of antibodies to Toxoplasma gondii. Journal of Clinical Microbiology 26 (11): 2444-2446.

17. Sambrook J., Fritch E.F. \& Maniatis T. (1989). Molecular Cloning, a Laboratory Manual.pp.18.6-18.61 Cold Spring Harbor Laboratory Press, 1 Bungtown Road, Cold Spring Harbor, New York.

18. Gasbarre L.C., Suter P. \& Fayer R. (1984). Humoral and cellular immune responses in cattle and sheep inoculated with Sarcocystis. American Journal of Veterinary Research 45: 1592-1596.

19. Lunde M.N. \& Fayer R. (1977). Serologic tests for antibody to Sarcocystis in cattle. Journal of Parasitology 63 (2): 222-225. 